\title{
Analysis of Determination of Position Based on Contribution of Task And Work Achievement
}

\author{
Misbahul Munir ${ }^{1}$, Yoniv Erdianto ${ }^{2}$, Suparto $^{3}$, Suparjo $^{4}$ \\ ${ }^{1}$ Lecturer, Department of Electrical Engineering, Institut Teknologi Adhi Tama Surabaya, Indonesia \\ ${ }^{2,3,4}$ Lecturer, Department of Industrial Engineering, Institut Teknologi Adhi Tama Surabaya, Indonesia \\ Email: munir@itats.a.id, yoniv@itats.ac.id, suparto@itats.ac.id,suparjo@itats.ac.id
}

\begin{abstract}
To find the value of employee achievement requires several aspects such as intelligence, aspects of work attitudes, and behavioral. The initial stage of the process is to find the difference between employee and position profile that has been determined by the company where it is called GAP. The next step is to determine the weight of each gap value in three aspects. We multiply the value of $60 \%$ for the value of the main factor and $40 \%$ for additional factors then add up the two factors to determine the total value. The three factors are assessed based on the percentage determined by the company, namely 25\% Intelligence Aspect, 35\% Behavioral Aspect, and 40\% Work Attitude Aspect. The final results are ranked, and then top ranking is achieved until the last employees who occupy the position of Project Supervisor are employees with ID number: kka_0001. For employees who are likely to fill the position of Purchasing \& Logistics are employees with ID number: kka_0040. For employees who are likely to occupy the Estimator position are employees with ID number: kka_0036. For employees who fill the Project Manager position are employees with ID number: kka_0055.
\end{abstract}

Keywords: matching, profile, gap, intelligence, aspect, attitude, behavioral

\section{Introduction}

One critical element in a company is Human Resources (HR). The HR manager of a company greatly influences many aspects that determine the success of the company's work. If HR can be organized properly, it is expected that the company can run all its business processes well [1]. There are several HR management constraints, one of which is that if a company has a large number of employees, then the planning of the career path of each employee and regeneration/change of positions within the company becomes difficult and takes up a lot of time because each personal [2]. Human Resource Department (HRD) is not necessarily getting to know each employee intimately, this will be a significant obstacle to develop the career path of each employee and regeneration/change of position because these must be based on the competency of each position and employee concerned [3].

To facilitate the implementation of the regeneration and career paths of each employee, a program system is created that aims to facilitate the process, prepare, and introduce targets (in this case, employees) in promoting the preparation of career paths and regeneration of the company organizations [4]. In this study, the program system will be run on the company PT. X engaged in the service of managing port permits and transportation of goods for sea transportation, which has a relatively large number of employees is large so that it is expected to represent the problem to be studied. One example that will be highlighted in this case is the way to select employees in accordance with the criteria that exist in a particular position. So if there is a position on the part of the company that is empty so that it is needed to be filled by employees, then, in this case, the task is to analyze employees who, according to calculations, fit the criteria of the position, at PT. This term X is called Competency Analysis (Profile Matching Analysis). The competency system will describe the achievements and potential of HR in accordance with the work unit [5, 6]. Employee achievement and potential can be seen whether the competency is in accordance with the work duties they have.

The program system that will be created will try to help overcome the problems that occur above so that HR can be utilized efficiently and effectively [7]. The system created will be more to assist 
managers in making decisions and not replace them; it is hoped that the operation can also increase the effectiveness and efficiency of the decision-making process itself $[8,9]$.

\section{Literature Review}

\subsection{Job Position}

Understanding Position A group of positions that have the same obligations or duties as the main tasks. In job analysis, one job can be occupied by one person or several people in a place [10]. Job description is a list of duties, responsibilities, report relations, working conditions, responsibility for supervising a position[11]. This information, in turn, is used to carry out work in a manner satisfying [12]. There are ten benefits that can be drawn from the assessment The work achievements are [13]: (a) Improved work performance; (b) Adjustment of compensation adjustments; (c) Decision on placement decisions; (d) Deviations from the staffing process; (e) Career planning and development; (f) Job design error.

\subsection{The Profile Matching}

The Profile Matching process is carried out to determine employee recommendations in the Promotion System and Career Planning based on three aspects, namely Intellectual Capacity, Work Attitude, and Behavior [14]. The results of this process are employee rankings as a recommendation for decision-makers to choose employees who are suitable for the vacant position [15].

\section{Method}

In Figure 1 below are the steps of the research stages.

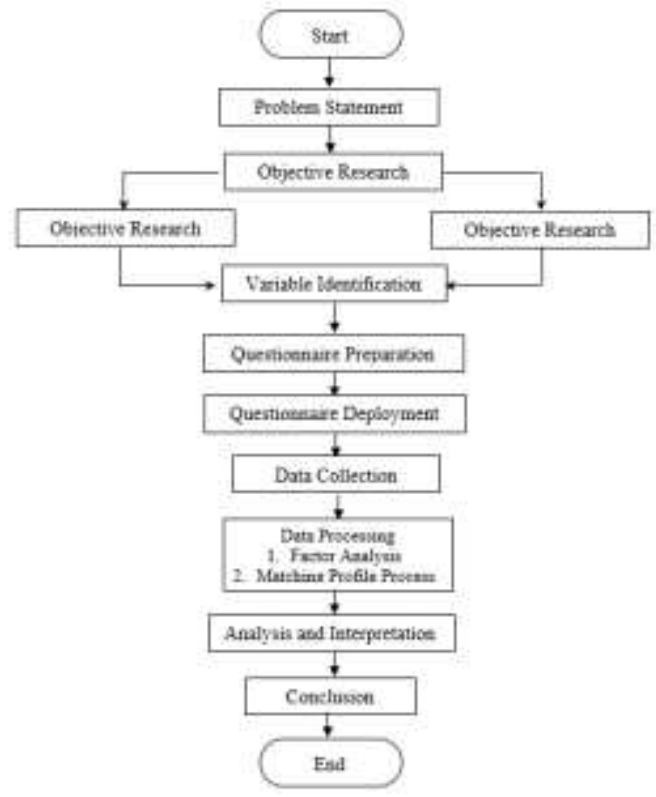

\section{Results and Discussion}

Figure 1. Research Methodology

\subsection{Profile Matching}

Profile Matching is a decision-making mechanism assuming that there is an ideal level of predictor variables that must be met by the subjects studied, rather than the minimum level that must be met or passed. Steps to the Profile Marching Method: (1) Determine aspects and sub aspects to be measured and assessed; (2) Determine the minimum standard value for each element; (3) Classifying sub aspects into the Main Factors, and Additional Factors; (4) Look for GAP values; (5) Determine the weight based on 
GAP; (6) Calculate NSF and NCF; (7) Calculating the Total Value; (8) Perform ranking process based on the total value/

\subsection{Competency Gap}

In the process of employee performance appraisal, problems often include the subjectivity of decision making, especially if several existing employees have abilities (and a few other considerations) are not much different.

\subsubsection{Competency Gap Mapping Variables}

The variables and methods of calculation used in the mapping are consists of aspects, including the following:

a. Intellectual Capacity, which describes intelligence, intelligence, or ability to solve the problem at hand, has aspects including: (1) Common Sense is the knowledge of someone to understand and perceive as well decide on a particular situation directly; (2) Verbalization of Ideas i.e. one's ideas or thoughts which are expressed in the form of words words so that their ideas can be understood by other people, or in other words delivery opinion; (3) Systematic Thinking is how someone expresses a his opinion; (4) Reasoning and Real Solutions (4) that is a person's attitude to answer and solve a problem; (5) Concentration is the concentration of attention, mind and spirit and physically on an object; (6) Practical Logic is a practical thought which is adapted to reasonable circumstances; (7) Thinking Flexibility is ease in one's way of thinking; (8) Creative Imagination is the Imagination carried out by doing a good creative process conceptually, ideas and actions by changing in various ways and through a different process; (9) Anticipation is perception of opinion formed before a thing happens.

b. Work Attitudes, which describe the tendency to behave in work, and results from work which is a function of motivation and ability, has the following aspects: (1) Psychic Energy (EP) is an energy that carries out the purposes of one's personality; (2) Accuracy and Responsibility (KT) is a person's ability to observe something complicated things and can solve a problem that he did; (3) Carefulness (KH) is a person's behavior in doing an activity; (4) Feeling Control (PP), that is a control in terms of emotions to be able to adjust to environmental conditions; (5) Encouragement of Achievement (DB) is a form of motivation in terms of work to be able to better in the future; (6) Vitality and Planning (VP) is the resilience and structuring of a matter to be done; (7) Behavior, with aspects between others: [1] Dominance (D) is a condition of one's power or position in its environment; [2] Influence (I) is an influence caused by someone on the situation in around it; [3] Steadiness ( $\mathrm{S}$ ) is a person's determination or determination in a matter; [4] Compliance (C) which is a form of social influence that is influenced by demand directly or indirectly from others.

\subsubsection{Competency Gap Mapping Calculation Process}

In this case, what is meant by the gap here is the difference between the position profile with employee profile or can be indicated in the formula below.

$$
\text { Employee Profile - Job Profile }
$$

Table 1. Intelligence Aspects

\begin{tabular}{|l|c|c|c|c|c|c|c|c|c|c|}
\hline \multirow{2}{*}{ Position } & \multicolumn{10}{|c|}{ Position Profile Value } \\
\cline { 2 - 14 } & 1 & 2 & 3 & 4 & 5 & 6 & 7 & 8 & 9 & 10 \\
\hline Project Supervisor & 3 & 4 & 4 & 4 & 4 & 4 & 5 & 5 & 4 & 4 \\
\hline Purchasing \& Logistic & 3 & 3 & 5 & 3 & 5 & 4 & 4 & 4 & 4 & 4 \\
\hline Estimator & 3 & 3 & 5 & 4 & 5 & 3 & 3 & 3 & 5 & 4 \\
\hline Project Manager & 5 & 5 & 5 & 4 & 5 & 4 & 3 & 5 & 5 & 4 \\
\hline
\end{tabular}


Table 1 explain It that the Employee Profit is the value of the profiles obtained from each - each employee, while the job profile is the value set by the company as an essential reference employee assessment.

Table 2 explain value for the position profiles listed in each are Project Manager, Project Supervisor, Purchasing \& Logistics, and Estimator. In Table 3 is the value of each position profile set by the company is as the following: Intelligence Aspects.

Table 2. Work Attitude Aspects

\begin{tabular}{|l|c|c|c|c|c|c|}
\hline \multirow{2}{*}{ Position } & \multicolumn{6}{|c|}{ Position Profile Value } \\
\cline { 2 - 7 } & 1 & 2 & 3 & 4 & 5 & 6 \\
\hline Project Supervisor & 3 & 5 & 4 & 4 & 3 & 3 \\
\hline Purchasing \& Logistic & 3 & 4 & 5 & 3 & 3 & 4 \\
\hline Estimator & 3 & 5 & 3 & 3 & 4 & 4 \\
\hline Project Manager & 5 & 5 & 4 & 4 & 5 & 4 \\
\hline
\end{tabular}

Table 3. Behavior Aspects

\begin{tabular}{|c|c|c|c|c|}
\hline \multirow[t]{2}{*}{ Position } & \multicolumn{4}{|c|}{$\begin{array}{c}\text { Position Profile } \\
\text { Value }\end{array}$} \\
\hline & 1 & 2 & 3 & 4 \\
\hline Project Supervisor & 4 & 4 & 4 & 3 \\
\hline Purchasing \& Logistic & 3 & 4 & 5 & 3 \\
\hline Estimator & 3 & 3 & 4 & 5 \\
\hline Project Manager & 5 & 5 & 4 & 4 \\
\hline
\end{tabular}

1. Intelligence Aspects

Data obtained by the questionnaire assessed by company managers through 3 aspects. Furthermore, all employee data are collected.

Table 4. Employee Profile Data for Intelligence Aspect

\begin{tabular}{|c|l|c|c|c|c|c|c|c|c|c|c|}
\hline No. & id_employee & 1 & 2 & 3 & 4 & 5 & 6 & 7 & 8 & 9 & IQ \\
\hline 1. & KKA_0001 & 3 & 3 & 5 & 2 & 3 & 4 & 3 & 3 & 2 & 4 \\
\hline 2. & KKA_0002 & 2 & 2 & 2 & 4 & 1 & 3 & 5 & 1 & 3 & 3 \\
\hline 3. & KKA_0003 & 3 & 4 & 3 & 2 & 2 & 3 & 2 & 2 & 2 & 2 \\
\hline 4. & KKA_0004 & 3 & 1 & 5 & 3 & 3 & 3 & 4 & 2 & 3 & 4 \\
\hline 5. & KKA_0005 & 4 & 2 & 4 & 3 & 5 & 4 & 3 & 5 & 1 & 3 \\
\hline
\end{tabular}

Table 4 illustrates a part of the surveyed employees.

Table 5. The gap on Intelligence Aspects of Project Supervisor Position

\begin{tabular}{|c|l|c|c|c|c|c|c|c|c|c|c|}
\hline \multicolumn{2}{|c|}{ Supervisor Project } & 3 & 4 & 4 & 4 & 4 & 4 & 5 & 5 & 4 & 4 \\
\hline 1 & KKA_0001 & 0 & -1 & 1 & -2 & -1 & 0 & -2 & -2 & -2 & 0 \\
\hline 2 & KKA_0002 & -1 & -2 & -2 & 0 & -3 & -1 & 0 & -4 & -1 & -1 \\
\hline 3 & KKA_0003 & 0 & 0 & -1 & -2 & -2 & -1 & -3 & -3 & -2 & -2 \\
\hline 4 & KKA_0004 & 0 & -3 & 1 & -1 & -1 & -1 & -1 & -3 & -1 & 0 \\
\hline 5 & KKA_0005 & 1 & -2 & 0 & -1 & 1 & 0 & -2 & 0 & -3 & -1 \\
\hline
\end{tabular}

Table 5 show find the competency gap in the position of the Project Supervisor.

2. Work Attitude Aspects

From the data obtained by the questionnaire, which was assessed by the company manager. Then at getting the data below.

Table 6. Employee Profi Data for Aspects of Work Attitude

\begin{tabular}{|c|l|c|c|c|c|c|c|}
\hline No. & id_employee & EP & KT & KH & PP & DB & VP \\
\hline 1. & KKA_0001 & 3 & 4 & 4 & 4 & 3 & 3 \\
\hline 2. & KKA_0002 & 4 & 3 & 5 & 3 & 2 & 4 \\
\hline 3. & KKA_0003 & 2 & 2 & 3 & 5 & 3 & 3 \\
\hline 4. & KKA_0004 & 3 & 2 & 2 & 4 & 4 & 2 \\
\hline 5. & KKA_0005 & 5 & 3 & 3 & 3 & 4 & 4 \\
\hline
\end{tabular}

Table 6 show aspect of work attitude in each individual at aspects such work alacrity, responsibility and accuracy in doing work 
Table 7. The gap for Work Attitude Aspects at Project Manager Position

3. Behavioral Aspects

\begin{tabular}{|c|c|c|c|c|c|c|c|}
\hline \multicolumn{2}{|c|}{ Project Manager } & 5 & 5 & 4 & 4 & 5 & 4 \\
\hline 1. & KKA_0001 & -2 & -1 & 0 & 0 & -2 & -1 \\
\hline 2. & KKA_0002 & -1 & -2 & 1 & -1 & -3 & 0 \\
\hline 3. & KKA_0003 & -3 & -3 & -1 & 1 & -2 & -1 \\
\hline 4. & KKA_0004 & -2 & -3 & -2 & 0 & -1 & -2 \\
\hline 5. & KKA_0005 & 0 & -2 & -1 & -1 & -1 & 0 \\
\hline
\end{tabular}

From the data obtained by the questionnaire, which was assessed by the company manager.

Table 8. Employee Profile Data for Behavior Aspects

\begin{tabular}{|c|l|c|c|c|c|}
\hline No. & id_employee & D & I & S & C \\
\hline 1. & KKA_0001 & 3 & 2 & 4 & 3 \\
\hline 2. & KKA_0002 & 4 & 4 & 3 & 2 \\
\hline 3. & KKA_0003 & 5 & 2 & 4 & 4 \\
\hline 4. & KKA_0004 & 2 & 3 & 2 & 3 \\
\hline 5. & KKA_0005 & 3 & 4 & 3 & 2 \\
\hline
\end{tabular}

Table 8 show profile data for behavior aspects by considering aspects such as discipline, responsibility and wholeness.

Table 9. The gap for Behavior Aspects of Project Supervisor Position

\begin{tabular}{|c|l|c|c|c|c|}
\hline \multicolumn{2}{|c|}{ Supervisor Project } & 4 & 4 & 4 & 3 \\
\hline 1. & KKA_0001 & -1 & -2 & 0 & 0 \\
\hline 2. & KKA_0002 & 0 & 0 & -1 & -1 \\
\hline 3. & KKA_0003 & 1 & -2 & 0 & 1 \\
\hline 4. & KKA_0004 & -2 & -1 & -2 & 0 \\
\hline 5. & KKA_0005 & -1 & 0 & -1 & -1 \\
\hline
\end{tabular}

Table 9. Then to look for competency gaps than in the position of Project Data Supervisor at subtracted by the Position.

\section{Profile Weighing Process}

After obtaining each gap from each employee, each profile is given value weights with a benchmark weight value gap table. The provisions of the weight value can be seen in Chapter II Table 2.5 Table of the gap value weights.

a. Weighting Aspects of Intelligence

From the data obtained, the calculation of competency gaps. Then for the position of Supervisor,

The project gets the data below. For more details, see the attachment.

Table 10. Weighting Aspects of Intelligence Position of Project Supervisor

\begin{tabular}{|c|l|c|c|c|c|c|c|c|c|c|c|}
\hline No & id_employee & 1 & 2 & 3 & 4 & 5 & 6 & 7 & 8 & 9 & IQ \\
\hline 1. & KKA_0001 & 5 & 4 & 4,5 & 3 & 4 & 5 & 3 & 3 & 3 & 5 \\
\hline 2. & KKA_0002 & 4 & 3 & 3 & 5 & 2 & 4 & 5 & 1 & 4 & 4 \\
\hline 3. & KKA_0003 & 5 & 5 & 4 & 3 & 3 & 4 & 2 & 2 & 3 & 3 \\
\hline 4. & KKA_0004 & 5 & 2 & 4,5 & 4 & 4 & 4 & 4 & 2 & 4 & 5 \\
\hline 5. & KKA_0005 & 4,5 & 3 & 5 & 4 & 4,5 & 5 & 3 & 5 & 2 & 4 \\
\hline
\end{tabular}

b. Weighting Aspects of Work Attitude

From the data obtained, the calculation of competency gaps. Then for the position of Supervisor.

The project gets the data below.

Table 11. Weighting Aspects of Work Attitudes in Project Supervisor Position 
c. Weighting the Behavioral Aspect

\begin{tabular}{|c|l|c|c|c|c|c|c|}
\hline No. & id_employee & EP & KT & KH & PP & DB & VP \\
\hline 1. & KKA_0001 & 5 & 4 & 5 & 5 & 5 & 5 \\
\hline 2. & KKA_0002 & 4,5 & 3 & 4,5 & 4 & 4 & 4,5 \\
\hline 3. & KKA_0003 & 4 & 2 & 4 & 4,5 & 5 & 5 \\
\hline 4. & KKA_0004 & 5 & 2 & 3 & 5 & 4,5 & 4 \\
\hline 5. & KKA_0005 & 3,5 & 3 & 4 & 4 & 4,5 & 4,5 \\
\hline
\end{tabular}

From the data obtained, the calculation of competency gaps. Then for the position of Supervisor Projects, get the data below.

Table 12. Project Supervisor Behavior Position

\begin{tabular}{|c|l|c|c|c|c|}
\hline No. & id_employee & D & I & S & C \\
\hline 1. & KKA_0001 & 4 & 3 & 5 & 5 \\
\hline 2. & KKA_0002 & 5 & 5 & 4 & 4 \\
\hline 3 & KKA_0003 & 4,5 & 3 & 5 & 4,5 \\
\hline 4. & KKA_0004 & 3 & 4 & 3 & 5 \\
\hline 5. & KKA_0005 & 4 & 5 & 4 & 4 \\
\hline
\end{tabular}

\subsubsection{Calculation and Grouping of Core and Secondary Factors}

After determining the weight of the gap value for the three aspects, namely aspects of intellectual capacity, work attitude, and behavior in the same way. Then each element is grouped again into two groups, namely Core Factor and Secondary Factor groups. Where is Core Factor is the main factor used as a reference for the company, and the Secondary Factor is an additional factor used for company valuation as a reference for making decisions.

Below is the formula used to find the average value of the main elements and additions

$$
N C I=\frac{\sum N C}{\sum I C}
$$

Where: NCI: The average value of intellectual core factors ; NC: The total number of intellectual core factor values ; IC: Number of core factor items

Whereas the secondary factor calculation can be shown in the formula below:

$$
N S I=\frac{\sum N S}{\sum I S}
$$

Where:

NSI: The average value of a secondary intellectual factor; NS: The total number of intellectual secondary factor values; IS: Number of secondary factor items

Table 13. Average Rating Table of Main Factors and Additional Aspects of Intelligence Position of Project Supervisor

\begin{tabular}{|c|l|c|c|c|c|c|c|c|c|c|c|c|c|}
\hline No. & id_employee & 1 & 2 & 3 & 4 & 5 & 6 & 7 & 8 & 9 & IQ & Prime Factor & Secondary Factor \\
\hline 1. & KKA_0001 & 5 & 4 & 4,5 & 3 & 4 & 5 & 3 & 3 & 3 & 5 & 3,2 & 4,7 \\
\hline 2. & KKA_0002 & 4 & 3 & 3 & 5 & 2 & 4 & 5 & 1 & 4 & 4 & 3,4 & 3,6 \\
\hline 3. & KKA_0003 & 5 & 5 & 4 & 3 & 3 & 4 & 2 & 2 & 3 & 3 & 2,6 & 4,2 \\
\hline 4. & KKA_0004 & 5 & 2 & 4,5 & 4 & 4 & 4 & 4 & 2 & 4 & 5 & 3,6 & 4,1 \\
\hline 5. & KKA_0005 & 4,5 & 3 & 5 & 4 & 4,5 & 5 & 3 & 5 & 2 & 4 & 3,7 & 4,3 \\
\hline
\end{tabular}

Table 14. Evaluation Table Average Main Factors and Additional Aspects of Work Attitude of Project Supervisor Position

\begin{tabular}{|c|l|c|c|c|c|c|c|c|c|}
\hline No. & id_employee & EP & KT & KH & PP & DB & VP & Prime Factor & Secondary Factor \\
\hline 1. & KKA_0001 & 5 & 4 & 5 & 5 & 5 & 5 & 4,67 & 5 \\
\hline 2. & KKA_0002 & 4,5 & 3 & 4,5 & 4 & 4 & 4,5 & 3,67 & 4,5 \\
\hline 3. & KKA_0003 & 4 & 2 & 4 & 4,5 & 5 & 5 & 3,83 & 4,33 \\
\hline 4. & KKA_0004 & 5 & 2 & 3 & 5 & 4,5 & 4 & 3,83 & 4 \\
\hline 5. & KKA_0005 & 3,5 & 3 & 4 & 4 & 4,5 & 4,5 & 3,83 & 4 \\
\hline
\end{tabular}


Table 15. Evaluation of Main Factors and Additional Behavioral Aspects of Project Supervisor Position

\begin{tabular}{|c|l|c|c|c|c|c|c|}
\hline No. & id_employee & D & I & S & C & Prime Factor & Secondary Factor \\
\hline 1. & KKA_0001 & 4 & 3 & 5 & 5 & 4,5 & 4 \\
\hline 2. & KKA_0002 & 5 & 5 & 4 & 4 & 4,5 & 4,5 \\
\hline 3. & KKA_0003 & 4,5 & 3 & 5 & 4,5 & 4,75 & 3,75 \\
\hline 4. & KKA_0004 & 3 & 4 & 3 & 5 & 3 & 4,5 \\
\hline 5. & KKA_0005 & 4 & 5 & 4 & 4 & 4 & 4,5 \\
\hline
\end{tabular}

\section{Calculation of the Total Value of Each}

Aspect From the calculation of the average value of the Main and Additional Factors from each aspect above, then calculated the total value based on the percentage of core and secondary estimated to affect each profile's performance. To get the assessment used, the formula below.

$$
\mathrm{N}=60 \% \mathrm{NCL}+40 \% \mathrm{NSI}
$$

Where: N: Total Aspect Value; NCI: The average value of intellectual core factors

NSI: The average value of a secondary intellectual factor

For the Intelligence Aspect, the $\mathrm{Ni}$ symbol is used for the total value of the Intellectual/intelligence aspect, where the calculation results are as follows:

Table 16. Value Percentage of Total Intelligence Aspects of Project Supervisor Position

\begin{tabular}{|c|l|c|c|c|}
\hline No. & id_employee & Prime Factor & Secondary Factor & $\mathrm{Ni}$ \\
\hline 1. & KKA_0001 & 3,2 & 4,7 & 3,8 \\
\hline 2. & KKA_0002 & 3,4 & 3,6 & 3,48 \\
\hline 3. & KKA_0003 & 2,6 & 4,2 & 3,24 \\
\hline 4. & KKA_0004 & 3,6 & 4,1 & 3,8 \\
\hline 5. & KKA_0005 & 3,7 & 4,3 & 3,94 \\
\hline
\end{tabular}

Table 17. Value Percentage of Total Aspects of Work Attitude of Project Supervisor Position

\begin{tabular}{|c|c|c|c|c|}
\hline No. & id_employee & Prime Factor & Secondary Factor & Ns \\
\hline 1. & KKA_0001 & 4,67 & 5 & 4,8 \\
\hline 2. & KKA_0002 & 3,67 & 4,5 & 4 \\
\hline 3. & KKA_0003 & 3,83 & 4,33 & 4,03 \\
\hline 4. & KKA_0004 & 3,83 & 4 & 3,9 \\
\hline 5. & KKA_0005 & 3,83 & 4 & 3,9 \\
\hline
\end{tabular}

Table 18. Value Percentage of Total Aspects of Behavior of Project Supervisor Position

\section{Ranking Calculation}

\begin{tabular}{|c|c|c|c|c|}
\hline No. & id_karyawan & Prime Factor & Secondary Factor & Np \\
\hline 1. & KKA_0001 & 4,5 & 4 & 4,3 \\
\hline 2. & KKA_0002 & 4,5 & 4,5 & 4,5 \\
\hline 3. & KKA_0003 & 4,75 & 3,75 & 4,35 \\
\hline 4. & KKA_0004 & 3 & 4,5 & 3,6 \\
\hline 5. & KKA_0005 & 4 & 4,5 & 4,2 \\
\hline
\end{tabular}

The final result of the profile matching process is the ranking of candidates submitted to fill a particular position. The determination of classification refers to the effects of specific calculations. The calculation can be shown in the formula below:

$$
\text { Ranking }=25 \% N i+40 \% N s+35 \% N p
$$

Where: Ni: Intellectual Capacity Value; Ns: Work Attitude Value; NP: Behavior Value

A calculation of the value of the total aspect for the position of the Project Supervisor can be seen in the Total Results Table Assessment of Project Supervisor Position Aspects in the Table 19.

Table 19. Project Supervisor Position Ranking

\begin{tabular}{|c|c|r|}
\hline \multicolumn{3}{|c|}{ Ranking } \\
\hline No. & id_karyawan & Hasil Akhir \\
\hline 1. & KKA_0001 & 4,38 \\
\hline 2. & KKA_0051 & 4,37 \\
\hline 3. & KKA_0009 & 4,33 \\
\hline 4. & KKA_0059 & 4,32 \\
\hline
\end{tabular}




\begin{tabular}{|c|l|r|}
5. & KKA_0045 & 4,31 \\
\hline 6. & KKA_0006 & 4,3 \\
\hline 7. & KKA_0040 & 4,29 \\
\hline 8. & KKA_0033 & 4,26 \\
\hline 9 & KKA_0036 & 4,25 \\
\hline 10. & KKA_0012 & 4,22 \\
\hline
\end{tabular}

\section{Conclusion}

Determine positions on employees based on job contributions to the company, skills, and the work period of an employee, namely, Matching Profile. There are three aspects used to assess employee performance, namely the Aspect of Intelligence, Aspects of Work. Attitudes, and Aspects Behavior. To develop the results of the assessment for consideration of the determination of the position of position, namely by looking at employee performance rankings in the area of Project Supervisor, Purchasing \& Logistics, Estimator, and Project Manager. Where employees have the opportunity to occupy Project Supervisor positions are employees with ID number: kka_0001 and kka_0051. For employees who have the chance to fill Purchasing \& Logistics are employees with ID number: kka_0040 and kka_0001. For employees who have the opportunity to occupy Estimator positions are employees with ID number: kka_0036 and kka_0040. For employees who have the chance to fill the Project, the Manager position are employees with no ID: kka_0055 and kka_0006.

\section{References}

[1] M. Agussalim. 2017. Analysis Work Discipline and Work Spirit to Achievement Employees PT. Japfa. Saudi J. Bus. Manag. Stud., vol. 2, no. 3B, pp. 286-296.

[2] S. Takeda and F. Homberg. 2012. The effects of gender on group work process and achievement: an analysis through self-and peer-assessment. British Educational Research Journal.

[3] A. Burke. 2011. How To Use Groups Effectivley. J. Eff. Teach., vol. 11, no. 2, pp. 87-95.

[4] Z. Rusby. 2018. The influence of incentives on work achievement of agents in Takaful Keluarga insurance at Riau Agency representative office of Pekanbaru City (India). Espacios, vol. 39, no. 24.

[5] E. Ferdyna. 2019. Effect of work experience and work achievement to position promotion for young employees in Bukopin Sharia Bank, Sidoarjo Branch. Int. J. Innov. Technol. Explor. Eng, vol. 8, no. 7C2, pp. 45-50.

[6] K. G. Corley and G. D. A. 2011. Sahiwal. Acad. Management Rev, vol. 36, no. 1, pp. 12-32.

[7] A. Marchand and M. E. Blanc. 2010. The contribution of work and non-work factors to the onset of psychological distress: An eight-year prospective study of a representative sample of employees in Canada. J. Occup. Health, vol. 52, no. 3, pp. 176-185.

[8] J. M. Harackiewicz and C. S. Hulleman. 2010. The Importance of Interest: The Role of Achievement Goals and Task Values in Promoting the Development of Interest. Soc. Personal. Psychol. Compass, vol. 4, no. 1, pp. 42-52.

[9] S. Harkness. 2010. The Contribution of Womens Employment and Earnings to Household Income Inequality: A Cross-Country Analysis. Cent. Anal. Soc. Policy Dep. Soc. Policy Stud, no. June, pp. $1-47$.

[10] T. A. Judge, C. J. Thoresen, J. E. Bono, and G. K. Patton. 2001. Fudge-et-al_2003. Int. Prod. Variety, vol. 127, no. 3, pp. 376-407.

[11] K. Nilsson. 2003. Job access, workplace mobility and occupational achievement. Urban Stud, vol. 40, no. 11, pp. 2325-2327.

[12] B. Aziri. 2011. Job Satisfaction - a Literature Review. Manag. Res. Pract, vol. 3, no. 1, pp. 77-90.

[13] B. Fleet and N. B. Fouzder. 1975. Electrochemical behaviour of organotin compounds. Part I. Application to the determination of trialkyl- and triaryltin derivatives. J. Electroanal. Chem., vol. 63, no. 1, pp. 59-68.

[14] R. Prabowo, M. L. Singgih, P. D. Karningsih, and E. Widodo. 2020. New product development from inactive problem perspective in indonesian SMEs to open innovation. J. Open Innov. Technol. Mark. Complex., vol. 6, no. 1. 
[15] P. Trevithick. 2018. The 'Self' and 'Use of Self' in social work: A contribution to the development of a coherent theoretical framework. Br. J. Soc. Work, vol. 48, no. 7, pp. 1836-1854. 